\title{
Photocurrent Measurements in Cadmium Sulphide Thin Films
}

\author{
M.D.Sharma, A.Bhargava \\ Nanophysics laboratory, Department of Physics, Government Dungar College, Bikaner-334001 \\ DOI: 10.29322/IJSRP.11.01.2021.p10977 \\ http://dx.doi.org/10.29322/IJSRP.11.01.2021.p10977
}

\begin{abstract}
Cadmium Sulphide (CdS) thin films prepared using sintering method have been investigated. The response of light illumination on the photocurrent is measured and analyzed. The effect of deposition time of powdered samples on the photoconduction process in the films is reported and discussed.

Mention the abstract for the article. An abstract is a brief summary of a research article, thesis, review, conference proceeding or any in-depth analysis of a particular subject or discipline, and is often used to help the reader quickly ascertain the paper's purpose. When used, an abstract always appears at the beginning of a manuscript, acting as the point-of-entry for any given scientific paper or patent application.
\end{abstract}

Index Terms- Cadmium sulphide, chemical bath deposition, sintering, thin film, photoconduction

\section{INTRODUCTION}

Chalcogenide semiconductor thin films are being intensively investigated for low-cost photovoltaic and optoelectronic applications [1-4]. Cadmium sulfide (CdS) is commonly used as n-type semiconducting layer for heterojunction thin films solar cells [2]. Multilayered CdS films can be employed in the manufacture of the optoelectronic devices $[3,4]$. The deposition of $\mathrm{CdS}$ film has been explored by various authors using techniques such as, thermal evaporation, sputtering, molecular beam epitaxy, spray pyrolysis, chemical bath deposition and sintering method [4-9].

Among the II-VI semiconductors, CdS polycrystalline thin films is a representative material with many applications such as large area electronic devices and solar cells[10]. It has a wide direct band gap (2.42 eV), so has been used as a window material together with several semiconductors such as $\mathrm{CdTe}, \mathrm{Cu}_{2} \mathrm{~S}$ and $\mathrm{CuInSe}_{2}$ [3]. Also the interest in CdS thin films stems from its piezoelectric properties and potential laser applications [11]. Polycrystalline CdS films with different micro structures and properties of the $\mathrm{CdS}$ layer were fabricated by coating a number of CdS slurries, which consist of cadmium and sulphur powders, appropriate amount of ethylene glycol and various amount of $\mathrm{CdCl}_{2}$, on the sintered $\mathrm{CdS}$ films and by sintering the glass-CdS composites at various temperatures[12].

Now it is the time to articulate the research work with ideas gathered in above steps by adopting any of below suitable approaches:
The sintering method is relatively inexpensive, simple and convenient for the large area of deposition of II-IV compounds. The present work is an effort to prepare the CdS films using sintering method and to study the effect of deposition time of powdered samples of $\mathrm{CdS}$ on the photoconduction process in these films. The present work is an effort to prepare the CdS films using sintering method and to study the effect of deposition time of powdered samples of $\mathrm{CdS}$ on the photoconduction process in these films.

\section{EXPERIMENTAL DETAILS}

Commercially available glass substrates were used in the study. The substrates were first soaked in acetone for a minute and then dried in air. Thereafter, they were cleaned in isopropyl alcohol, washed with deionized water. Then the substrates were dried again in air before deposition of material [13].

The samples were prepared by chemical method using Cadmium Sulfide $(\mathrm{CdS})$ powders. There were three $\mathrm{CdS}$ powders which were prepared at deposition times of $60 \mathrm{~min}$, 90min and 120 min. [14]. CdS films were then prepared by the sintering technique [12]. For this, appropriate amount of Cadmium Chloride $\left(\mathrm{CdCl}_{2}\right)$ was added as an adhesive and ethylene glycol as the binder. The weight of $\mathrm{CdCl}_{2}$ was kept $10 \%$ of the weight of $\mathrm{CdS}$ powder. $\mathrm{CdS}$ and $\mathrm{CdCl}_{2}$ were thoroughly mixed and then a few drops of ethylene glycol was added to form the paste. The paste was then painted on the glass substrates. After sintering, films were dried in air at room temperature for 24 hours. The prepared films were annealed between at $463 \mathrm{~K}$ for 2 hours to make them homogeneous. After annealing, the colour of $\mathrm{CdS}$ thin film turns to dark yellow. The films are now well adhered to the glass plates and become uniform[12-14].

Light from an incandescent source was allowed to fall on the glass slide containing the film and a detector was mounted on the optical bench. The response of light illumination at various intensities was studied on the films. Photovoltage was measured using a digital multimeter (Aplab-Appa). The photocurrent versus intensity measurements were done using a nanoammeter (Omega).

\section{RESULTS AND DISCUSSION}

\section{A. Variation of Photovoltage with Intensity}

Figure1 shows the variation of photovoltage with light intensities at deposition times of $60 \mathrm{~min} ., 90 \mathrm{~min}$. and $120 \mathrm{~min}$. Generally, it is observed that with the increase in intensity, there 
is also an increase in photovoltage. The film deposited at $60 \mathrm{~min}$., show normal behavior. The photovoltage initially increases with intensity, then it becomes almost constant. For film deposited at $90 \mathrm{~min}$, the photovoltage increase is smaller compared to films deposited for $60 \mathrm{~min}$. In case of film deposited at $120 \mathrm{~min}$, the photovoltage has value between films deposited for $60 \mathrm{~min}$ and 90min., but overall response is similar to other films. The constant values obtained for photovoltage can be assigned to site saturation and depends on the growth of film[15].

The response of voltages on different deposition times for various intensities are approximately similar. It is observed that for maximum intensity, photovoltage for film deposited for 60 min. increases but photovoltage corresponding to deposition time of $90 \mathrm{~min}$. first decrease and then increase. Similarly, for other intensities, photovoltage starts increasing for films deposited for $60 \mathrm{~min}$, then it decreases for films deposited for $90 \mathrm{~min}$, and increases for films deposted for $120 \mathrm{~min}$. This can be due to optimum conditions reached for film growth for 90min duration and hence less number of carriers are available for excitation and conduction[14].

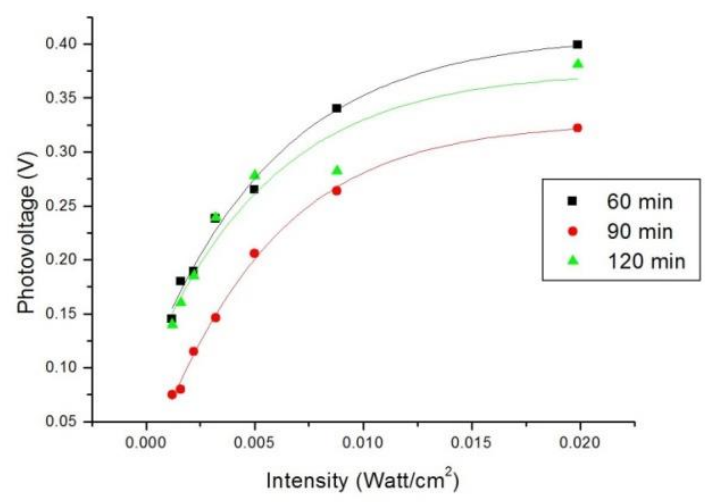

Figure 1 Variation of photovoltage with intensities for various deposition times

\section{B. Variation of Photocurrent with Deposition Time}

The variation of photocurrent measurements are displayed in figure 2-4. In all the cases, the variation of photocurrent is found to increase with time and then saturates to a almost constant value. Initially, high value of the photocurrent is due to the absorption of photon by the films, which excites the electrons from the valance band to conduction band. This creates pairs of free holes in valance band and free electrons in conduction band. Most of the electrons are from the surface of the CdS film which moves from valance band to conduction band, thereby it increasing the process of pair generation initially, which in turn increase the carrier concentration and hence the number of excited states.

When light is switched off, the current starts to fall rapidly and reached a certain minimum value which is approximately same for all the films deposited at different times. The photocurrent decrease with time and after some time, the photocurrent is almost constant. This occurs as the carrier concentration decreases with time. Also the process of recombination takes place with respect to time which decrease the value of current. A state is obtained where the process of generation of charge carrier and recombination reaches an equilibrium. This results in a constant photocurrent with respect to time. Here, surface recombination is very high and it leads to a lower carrier concentration at the surface which decreases the value of photo current.

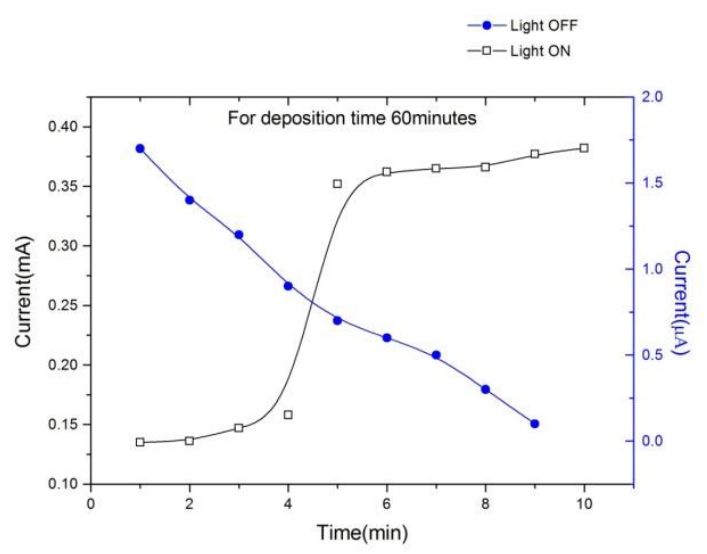

Figure 2 Variation of photocurrent with time for film deposited for $60 \mathrm{~min}$.

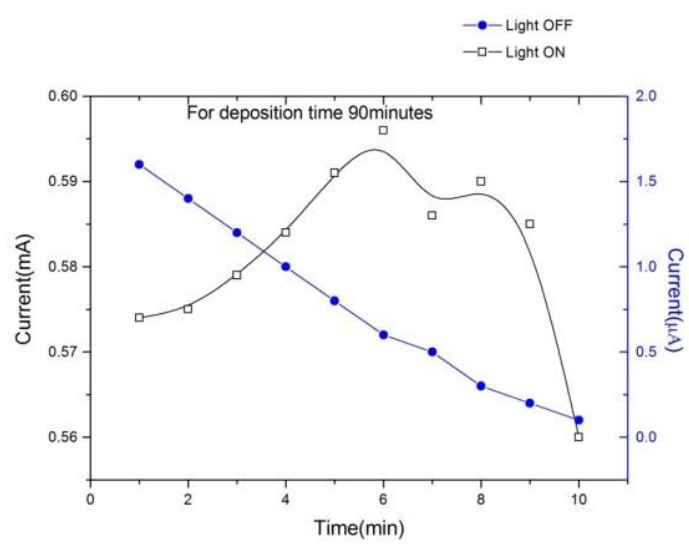

Figure 3.4 Variation of photocurrent with time for film deposited for $90 \mathrm{~min}$.

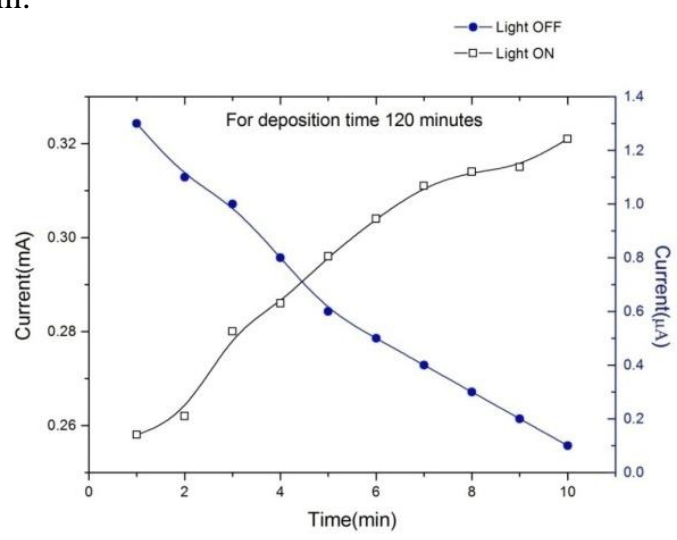

Figure 4 Variation of photocurrent with time for film deposited for $120 \mathrm{~min}$.

In CdS films, the Fermi level is located in the upper region of the forbiddenband and so chemical bath deposited CdS films are n- 
type. This is consistent with the common observed feature that $\mathrm{CdS}$ thin films are natively n-type [16]. It is worth noting that defects such as sulfur vacancy VS or Cd interstitial ICdS are donor defects in $\mathrm{CdS}$ thin films. Moreover, $\mathrm{CdS}$ thin films are generally $\mathrm{S}$ defective material, therefore, $\mathrm{CdS}$ thin films are natively n-type semiconductor. Due to sulfur volatility, S vacancies concentration is enhanced with increasing the deposition temperature and deposition time [17]. This induces an increase in the conductivity and the motion of Fermi level towards the bottom of conduction band edge. It is reported that an effective way to obtain $\mathrm{CdS}$ films with low resistivity and high optical transmittance can be achieved by the creation of excess $\mathrm{Cd}$ through various heat treatments and/or incorporation of foreign trivalent atoms as donors [18].

\section{CONCLUSION}

The CdS films have been prepared using the sintering technique from powdered samples prepared using chemical bath deposition. The films are found to be photoconductive and photosensitive in nature. The photovoltage values measured were found to increase with increase in intensity. At each of the measured intensities, with increase in deposition time, the photovoltage increase for film prepared at 60 and 120 min., but comparatively photovoltage decreases for film prepared at $90 \mathrm{~min}$. In the ON state, the photocurrent first increase and then it becomes constant. In the OFF state, current falls abruptly and attains a definite value. This indicates that the prepared films are photo sensitive and can be used as photosensor.

\section{REFERENCES}

1. Saha Sudipto, Michael Johnson, Fadhilah Altayaran, Youli Wang, Danling Wang, Qifeng Zhang, "Electrodeposition Fabrication of Chalcogenide Thin Films for Photovoltaic Applications", Electrochem, vol. 1(3) p.286 (2020).

2. R.S.Kapadnis, S.B.Bansode, A.T.Supekar, P.K.Bhujbal, S.S.Kale, S.R.Jadkar, H.M.Pathan, “ Cadmium Telluride/Cadmium Sulfide Thin Films Solar Cells: A Review", ES Energy \& Environment, vol.10 p.3-12 (2020).

3. Wu Jingjin, F.Ang, Zhao Cezhou and J.S.Smith (2020), "Electrical properties of N-type CdS and P-type CdTe thin films in CdS/CdTe solar cells" , Proceedings of the 20th IEEE International Symposium on the Physical and Failure Analysis of Integrated Circuits (IPFA), Suzhou, p.385-389 (2013) doi:10.1109/IPFA.2013.6599187.

4. Yang Dingyu, Zhu Xinghua, Wei Zhaorong, Yang Weiqing, Li Lezhong, Yang Jun, Gao Xiuying, Structural and optical properties of polycrystalline CdS thin films deposited by electron beam evaporation", Journal of Semiconductors, vol. 32(2) p.023001 (2011)

5. Ashwani Kumar, Vipin Kumar, Ramesh Chandra and Yogendra K Gautam, "Effect of sputtering process parameters on structural and optical properties of CdS thin films", Materials Research Express, vol.6(10) p.106448 (2019).
6. Paul Boieriu, Paul, Robert Sporken, Yan Xin, N.Browning, S. Sivananthan, "Wurtzite CdS on CdTe grown by molecular beam epitaxy", Journal of Electronic Materials vol.29 p.718 (2000)

7. Sundus M. A. Al-Dujayli , "Characterization of CdS Thin Films Grown by Spray Pyrolysis Deposition Using Different S/Cd Ratios", International Review of Physics,vol.6 p.409 (2012).

8. P. Agrawal, M. Sachdeva, Anupinder Singh, B. Suthar, A. Bhargava, "Structural and Optical Properties of Cds Thin Films Prepared by Chemical Bath Deposition", AIP Conf. Proc. Vol. 1536, p.165 (2013).

9. X. Mathew G. Pérez Hernández, J. Pantoja Enríquez, B. Escobar Morales, D. Martínez Hernández, L. Díaz Flores, C. Ricárdez Jiménez, N. R. Mathews, "A comparative study of $\mathrm{CdS}$ thin films deposited by different techniques", Thin Solid Films vol.535(1) p.154 (2012).

10. Bosio, Alessio \& Romeo, Nicola \& Mazzamuto, Samantha \& Canevari, Vittorio " Polycrystalline CdTe Thin Films for Photovoltaic Applications". Progress in Crystal Growth and Characterization of Materials. Vol. 52. P.247 (2006).

11. S.Thirumavalavana, K.Manib, S. Sagadevanc, "Studies On Structural, Optical And Electrical Properties Of Cadmium Sulphide Thin Films", Journal Of Ovonic Research, Vol. 11(5) p. 203 (2015)

12. D Patidar, R Sharma, N Jain , T P Sharma, N S Saxena , "Optical properties of CdS sintered fims", Bulletin of Materials Science, vol. 29(1) p.21 (2006).

13. P.Agrawal, M.Sachdeva, Anupinder Singh, B.Suthar, A.Bhargava, "Influence of Bath Parameters on the Structure and Optical Properties of CdSe NanocrystallineThin Films", AIP Conf. Proc. Vol. 1536 p.169 (2013).

14. P..Agrawal, Randhir Singh, Jeewan Sharma, M.Sachdev, Anupinder Singh, A.Bhargava, "Structural and Morphological Study of Chemically synthesized CdSe Thin Films", AIP Conference Proceedings, vol. 1953, p.030060 (2018).

15. K.Oura, M.Katayama, A.V.Zotov, V.G.Lifshits, A.A.Saranin, "Growth of Thin Films" in: Surface Science. Advanced Texts in Physics. Springer, Berlin, 2000, p.77.

16. O.A. Ileperuma, C. Vithana, K. Premaratne, S.N. Akuranthilaka, S.M. Mcgregor, I.M. Dharmadasa, "Comparison of $\mathrm{CdS}$ thin films prepared by different techniques for applications in solar cells as window materials", Journal of Material Science vol.9 p.367 (1998)

17. Hani Khallaf, Isaiah Oladeji, Guangyu Chai, Guangyu , Lee Chow, "Characterization of CdS thin films grown by chemical bath deposition using four different cadmium sources", Thin Solid Films vol. 516(21), p.7306 (2008)

18. B. J. Babu, S. Velumani, A. Kassiba, " Structural and dielectrical studies on mechano-chemically synthesized indium doped CdS nanopowders", J Mater Sci , vol.46 p.5417 (2011) 


\section{AUTHORS}

First Author-Dr. M.D.Sharma, M.Phil., PhD (Physics), Associate Professor, Government Dungar College, Bikaner. Email : mdsharma.phy@gmail.com
Second Author - Dr. A.Bhargava, M.Phil., PhD (Physics), Associate Professor, Government Dungar College, Bikaner. Email : anamib6@gmail.com

Correspondence Author - Dr. Anami Bhargava, Email : anamib6@gmail.com. 